\title{
INTERNATIONAL YOUTH SCIENTIFIC ENVIRONMENTAL FORUM OF THE BALTIC REGION COUNTRIES «ECOBALTICA»
}

\author{
Mikhail Fedorov \\ Vasiliy Rud' \\ Alexey Cheremisin \\ Saint-Petersburg State Polytechnic University, Russia
}

\begin{abstract}
The solution of global and local environmental problems demands consolidation of efforts of specialists (experts) from various areas of a science and technology. Education and training of ecologically competent experts is an essential task of a modern society for provision and maintenance of a favorable, ecologically safe environment for present and future generations of people on our planet. This purpose is served by widely known concept of the sustainable development which idea should be a basis in professional training specialists for various branches of a science, economy and education. The important means for exchange by experience, knowledge and designs between scientific and educational institutions, enterprises, companies, firms etc., are the international scientifically-practical conferences, seminars and forums. One of them is the International Youth Scientific Environmental Forum of the Baltic Region Countries «ECOBALTICA».

The history of carrying out of the Forum at the St.-Petersburg State Polytechnic University totals already almost 15 years. Some generations of young scientists and specialists who were regularly taking part in the Forum in this period, had time to be formed and grow. An aim of the Forum «ECOBALTICA» is consolidation of international experience of solution of applied and fundamental issues of ecology and environmental protection, as well as the problems connected with reproduction of highly skilled engineering and scientific manpower at domestic and international level. Interest to the Forum was shown by participants not only from the countries of the Baltic region, but from many far states to Baltic Sea. It is important to notice that long-term cooperation with University of Kalmar city, Sweden, has allowed organizers of the Forum «ECOBALTICA » to raise its efficiency and to deduce it on absolutely new organizational level.

As a result, there has been created in St.-Petersburg the system of measures directed to increase of efficiency of scientific and educational process in sphere of environmental protection, to develop bases of ecological culture of the people that has allowed to pass from discussion of scientific questions and education of qualified manpower, to direct influence on ecological conditions of the Baltic Region.
\end{abstract}

\section{KEYWORDS}

Baltic region, Kalmar city, Ecology, Forum «ECOBALTICA», Cooperation, Youth.

https://doi.org/10.15626/Eco-Tech.2010.073 


\section{INTRODUCTION}

Determination of biodegradable organic The idea of holding of a great traditional event for students and young scientists that would integrate various scientific areas to solve global problems was very important for Russia in the 90-s. During this period country's government was trying to develop a new economic system and didn't have time for science and education. After graduating young people reluctantly stayed in the University's research and teaching positions. There were problems in publishing scientific results in scientific periodicals etc.

On Academician of Russian Academy of Sciences Yuri Vasiliev's assignment young graduates of St. Petersburg State Polytechnic University (SPbSPU) undertook to solve this problem by arranging a regular scientific forum.

\section{WHY ENVIRONMENTAL YOUTH FORUM?}

The directions of engineering environmental protection, energy efficiency, technologies etc. were traditionally developed at the Polytechnic University. However for arranging this large traditional youth conference specialties and research areas of Hydrotechnical department (now Engineering and Construction Department), which had at least two leading chairs were chosen.

The main directions of scientific studies in environmental safety in SPbSPU have been:

- Environmental protection, research and development in nature and technical systems management in energetics;

- Environmental protection, research and development in nature and technical systems management in the water sector;

- Technologies for handling, disposal and recycling of production and consumption waste;

- Ecological and socio-economic study for transportation, energy systems and urban constructing;

- Evaluation of reliability and environmental safety in the industry, hydropower and water resources;

- Methods of rational use of resources and implementation of resource-saving technologies in housing and communal services and repair and construction operations;

- Physics-chemical, colloid-chemical and physic-technical methods of environmental monitoring, trace analysis of natural and potable water, wastewater, development of methodological support and research of surface, groundwater and drinking water;

- Rational design of city transport systems, use of underground spaces, region reconstruction in historic towns;

- Medical and ecological assessment of area and pollution impact on human health;

- Balancing of technogenic load on water bodies and modeling of contaminants in water bodies and streams;

- Eco-design as a method of improving air quality in enclosed spaces;

- Risk management and quantitative methods of its evaluation in technological and social spheres ;

- Safety of nuclear power stations and extension of their time of service;

- Energy and resource conservation in urban development and agriculture;

- Preservation and restoration of damaged land, landscape and biodiversity;

- Environmental engineering and optimization of biological resources use, water, biodiversity, conservation business; 
- Geoinformation technologies in the construction and applied ecology;

- Research in the field of recycling of road transport and its components;

- Methods of feasibility and environmental feasibility of parameters of energy facilities for the formation of investment potential, including the complex reconstruction and modernization;

- Expertise and information technologies to ensure efficiency and reliability of power plants and complexes based on renewable energy;

- Methods and comprehensive study of solar, bio, wind and hydropower plants on the basis of physical and mathematical modeling;

- Methods and computer design and mathematical modeling of hydropower and water facilities.

\section{HOW WE START “ECOBALTICA” FORUM}

That is why the main intention of Forum is cooperation of these wide areas of scientific works and scientific directions of physicists, chemists and engineers. Ecology and environmental protection was posed as a general problem. The idea of the Forum, which had been named ECOBALTICA, was supported by former mayor of St. Petersburg, Anatoly Sobchak. The city constantly supported the Forum. A young professor at the University of Kalmar in 1990-s, William Hogland took part in preparing for the draft of the first event for young people of this kind. With his help we had a great opportunity to establish contacts with leading foundations in Sweden, such as Swedish Institute, IVA and other companies. Subsequently, Professor William Hogland became the International Director of the ECOBALTICA. The University of Kalmar has always been supportive of the Forum, its professors were to review reports and lectures, and students presented their reports.

When the first Forum had been held successfully (in 1996, two years after preparations began) it became obvious that the ideas of the Forum are in time and important. A laboratory of ecology in the Baltic region was set up in St. Petersburg State Polytechnic University. The main goal of the laboratory was preparing and staging "ECOBALTICA" forum and developing scientific and innovative contacts and cooperating of the University and firms and other universities in the Baltic region.

By now we have already held 7 Forums in 1996, 1998, 2000, 2002, 2004, 2006, 2008. During that time more than 40 leading professors made their plenary lectures. Over 1000 young researchers made their reports. For many of participants it was the first presentation on the "ECOBALTICA Forum". Nowadays many young participants of the first Forum "ECOBALTICA' 1996" make reports as engaged speakers and their students make their first reports at the "ECOBALTICA Forum". It is the continuity of generations in science!

\section{GREAT THANKS THIS COMPANIES}

"ECOBALTICA Forum" was supported by The State Committee on Higher Education and Sciences of Russian Federation; St.-Petersburg City Administration; Kalmar Municipality, Sweden; ITT Flyght, Sweden; SWECO (VBB Viak), Sweden; IVL AB, Sweden; The Swedish Institute, Sweden; SYSAV AB, Sweden; Kalmar University College, Sweden; Vodokanal Saint-Petersburg, Russia; Russian State Program "INTEGRACIA"; St.Petersburg State Technical University, Russia; The Russian Foundation for Basic Researches; Energy Problems Departament of Russian Academy of Sciences, The Sustainable Sweden Southeast $\mathrm{AB}$, Sweden. We hope for our close collaboration! 


\section{YOU ARE WELCOME}

In May and June 2011 we will hold the International Scientific Forum on Environmental Protection for young people in the Baltic region "ECOBALTICA". It will be held in St. Petersburg again. And we invite students, graduates and their scientific advisers to take part in "ECOBALTICA-2011”! 